\title{
The Effects of Carbon Dioxide Laser Irradiation on Drilling of Limestone Included Crude Oil
}

\author{
Adeleh Granmayeh Rad1, Mohsen Bazargan², Ata Koohian', Hosein Jalalyfar ${ }^{2}$ \\ ${ }^{1}$ Department of Physics, Faculty of Sciences, Roudehen Branch, Islamic Azad University, Roudehen, Iran \\ ${ }^{2}$ Petroleum Engineering Department, Shahid Bahonar University of Kerman, Kerman, Iran \\ ${ }^{3}$ Department of Physics, University of Tehran, Tehran, Iran \\ Email: granmayeh@riau.ac.ir
}

Received 30 November 2013; revised 29 December 2013; accepted 25 January 2014

Copyright (C) 2014 by authors and Scientific Research Publishing Inc.

This work is licensed under the Creative Commons Attribution International License (CC BY).

http://creativecommons.org/licenses/by/4.0/

(c) (i) Open Access

\begin{abstract}
Laser rock spallation is a rock removal process that utilizes laser induced thermal stress to fracture and cause a break through the rock by creating small fragments before melting of the rock. In this paper we investigated the effects of $\mathrm{CO}_{2}$ laser irradiation on limestone of Iran Sarvak formation. Since the limestone included heavy and light oil, we studied the amount of laser beam absorption by this oils for determining thermal fractured during the laser drilling laboratory process. In order to characterize this limestone spectrophotometry (from UV to NIR), scanning electron microscopy (SEM) have been used.
\end{abstract}

\section{Keywords}

\section{Limestone Drilling; Rate of Penetration; $\mathrm{CO}_{2}$ Laser; Oil and Gas Well}

\section{Introduction}

The old method of drilling was rotary drilling and it was developing since the one century earlier, the basic method of using those illustrations is to safely reach out the gas and oil formations [1] [2], although those methods never get used to and had been proven to be successful technological [3] [4].

Large varieties of oil and gas wells data are available. These information include drilling reports, mud reports, production and completion reports, casing and cementing reports, etc. However, drilling cost analysis was focused on daily drilling reports just because of time and money saving caused some of the costs are time-dependent during drilling operation. Drilling time is reduced by increasing the rate of penetration (ROP) and this pa- 
rameter is affected in many parameters, such as hydraulics forces, weight on bit, rotary speed, type of bit, mud properties, formation characteristics and so on.

The potentials of all types of solid or gas lasers to drilling rock samples have been pointed out by many scientists and companies that have been working on mining and tunneling engineering. One of the most famous reports of laser drilling and interactions between laser and rock was published by Dr. Moavenzadeh since 1967, that lasers could be effective in the case of excavating rock samples [5]-[7].

Some other research groups which are active in oil and gas industry, work on many projects about laser and rock interactions [2] [8] or using laser set ups to drill the oil and gas wells. Some of the famous professors and groups that work on these fields are, Dr. Graves, Dr. Gahan, Mr. Parker and the Gas Technology Institute [8][17].

The advances have led to the recommending of a more efficient way of drilling [10] [14] [16]. Laser drilling can increase the rate of penetration by greater than 10 to 100 times over the conventional rotary drilling methods that depend on rock type they faced on, and the situation of down hole. After that the problems linked to dull drill bits wastes created from drilling mud [11] [13] [17].

\section{Feasibility}

\subsection{History}

The common lasers are used in manufacturing industry since they were only achieving the ability to reach this possibility in 20th century [18]. After years, different types of lasers with different evaluation were coming and commercially available to reach high powers. The especial evolution to development of down-hole laser drilling machines, including operations like laser-assisted drill bits, laser perforation tools, sidetrack laser drilling and directional laser drilling operation devices are all possible with the any sort of advancement of gas laser technology [19]. Lasers have already been applied to use industrially in the mining industry, eye surgery or other organs surgery, etc. [20] [21]. Penetrating works by enhancing the performance of tunneling machines have the history and knowledge for almost three decades [19]. According to advancements in laser technology, some experimental work on this topic has recently been undertaken and we tried to focus the drilling cost optimization [22]. Modeling of laser drilling process, cutting and scribing has been addressed by different researchers. Onedimensional drilling models and one-dimensional analytical heat conduction with laser energy incident on a metal surface model have been examined [23]. But the especial papers had been published by Mr. Blackwell, he has studied on high intensity energies and the effect of focusing them on metal or rock samples with different composition and concluded that a metal explosion below the surface occurs due to the effects of thermal stresses. And explained the material removal and vaporization by stating the maximum creature temperature induced inside the body because of the heat flux [17].

\subsection{Aim}

This paper is focused on investigating of thermal influences during prosier involved in laser drilling in limestone rock samples and responsible for material spalling and removal by the heat of laser drilling process. This process is directly effects on high-power laser systems such as gas lasers that one of the best and available of them is carbon dioxide $\left(\mathrm{CO}_{2}\right)$ lasers [6] [7] [24].

\subsection{Comparison}

Comparing lasers and the input energy needed for different industrial high-power lasers to generate the same output power [25] [26]. Assuming that, identical application of the experimental conditions, a typical lamppumped Nd:YAG laser would require as much as for times of electrical power as compared to with an Ytterbium fiber laser to send less than 0.2 times of laser energy to a target [27] [28]. This represents tiny little less input energy for the setup laser machines to achieve the same output power that we required [18] [22] [29].

Results shown in all cases related to rock failures that, the Young's modulus that related to the elasticity strength of the material, shear modulus and bulk modulus that related to elasticity and poisons ratio, and compressibility modulus near the lased portion, were the amount is reducing when compared to the samples that didn't intense with laser system [4] [5] [20].

In limestone rock samples, the decrease was obviously more [24]. Because we creating hole in intact sample 
that could initiate many micro fractures and macroscopic hole that pass throw the whole part of sample. Other parameters such as bulk modulus and shear modulus are decreased [3]. Causes the compressibility of the samples that could evaluate to the near wellbore condition had been increased by creating on hole and many cracks inside of it [3] [19]. Depending on the each lithology, Poisson's ratio decreased or increased slightly but no effective. For limestone, the differences between the module of samples that been lased and the samples that hadn't be lased were less significant than each other [3] [18].

\section{Experimental}

\subsection{Limestone Rock}

The Limestone rock used in this research was a limestone included of heavy and light crude oil of Iran Sarvak formation (Figure 1).

\subsection{Laser Irradiation}

Limestone was irradiated with a carbon dioxide laser beam suing E.Marion $\mathrm{CO}_{2}$ laser (E.Marion 4.2/260). The Beam was in wavelength of $10.6 \mu \mathrm{m}$. This wavelength is about 10 to 30 times longer than the other lasers under discussion like Nd:YAG and often considered to be a good source of a heat beam than a light beam.

The limestone samples were irradiated at single beam intensity in varying times. All experiments were performed using a laser power output of $50 \mathrm{~W}$. The limestone out crop samples were placed on a flat surface, below the laser beam head, during irradiation, so that as the beam irradiated the samples, the laser beam was perpendicular to the samples (Figure 2). In each time, laser irradiated $0.5 \mathrm{~mm}^{2}$ of the limestone.

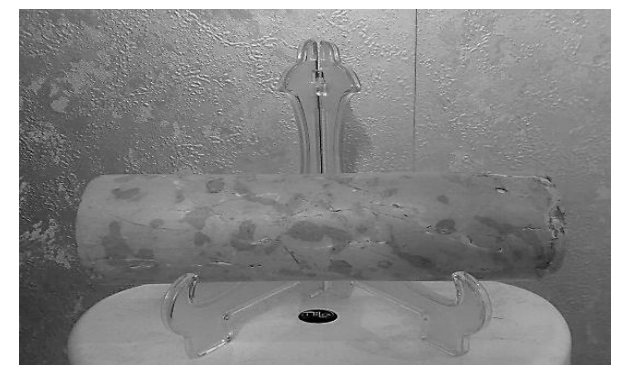

Figure 1. Limestone sample.

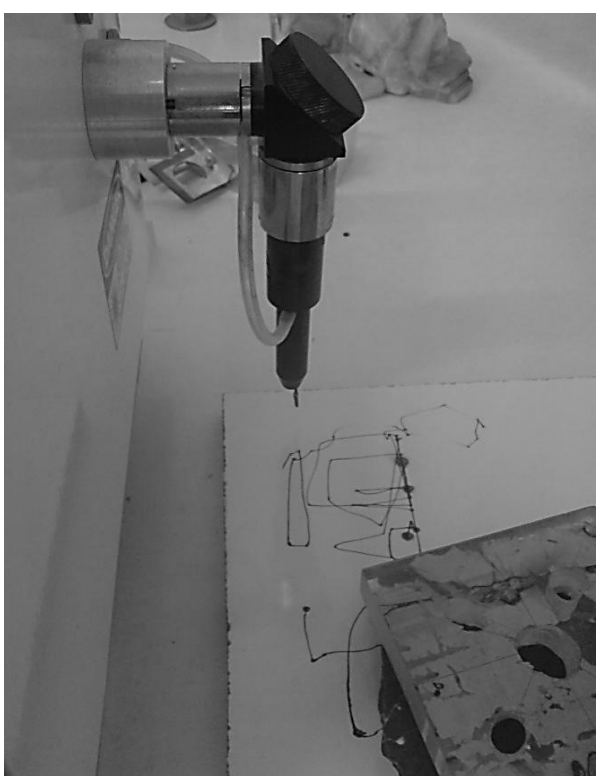

Figure 2. Laser $\mathrm{CO}_{2}$ system. 


\subsection{Characterizing of Limestone}

Since the limestone rock included by heavy and light crude oil which can absorb the main amount of laser beam power, absorption spectra of the heavy and light oil were measured by a Varian Cary-500 spectrophotometer at room temperature.

The morphology of the limestone rocks included by heavy and light oil was observed using a Scanning Electron Microscope (SEM) (DECTOR Bit) before and after laser irradiation.

\section{Results and Discussion}

\subsection{Spectrophotometry Results}

Divergence and diffraction effects are also increased by increasing of power of $\mathrm{CO}_{2}$ laser, so obtaining an efficiency of beam is also more difficult. Many common materials including wood, paper, plastics, polymers, composites, and metal surfaces have a good absorption peak at this wavelength. The UV-Visible-IR spectra of heavy oil and light oil are presented in Figures 3 and 4.

The results showed the absorption spectrum of heavy crude oil in comparison to light crude oil is much more.

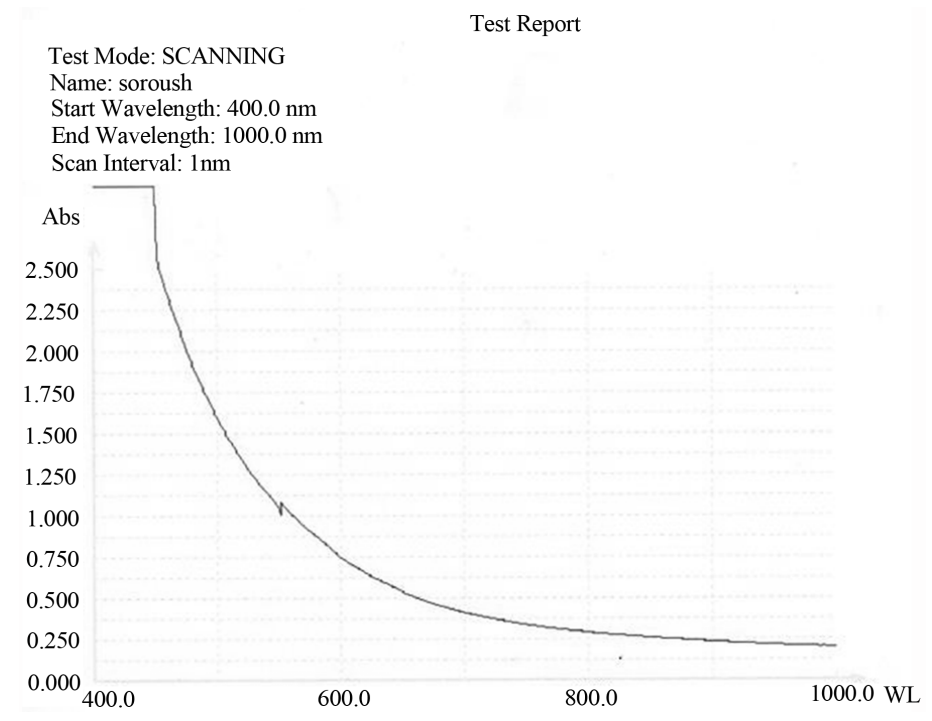

Figure 3. Absorption spectrum of heavy oil-API 11

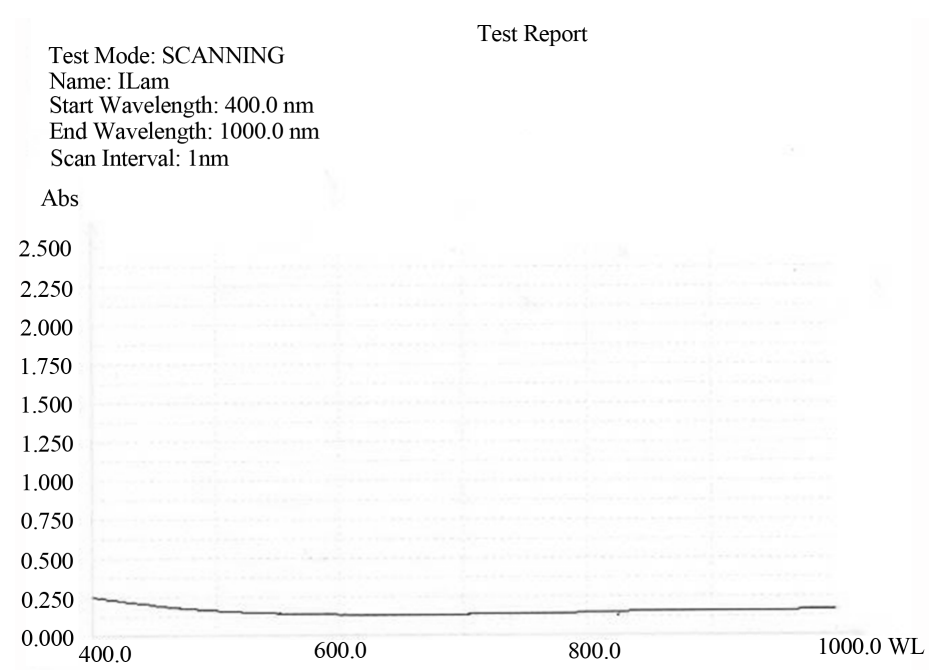

Figure 4. Absorption spectrum of light oil-API 34. 


\subsection{Morphological Studies}

Follow operation is a whole new operation in drilling industry and named as laser drilling laboratory process can spall the limestone in micro dimension (Figure 5).

To prove what this paper talk about is should be notified with some talkative images. Scanning electron microscope images are visualized the structural changes of limestone by laser irradiations. Figures 6(a) and (b) displays the limestone surface included light oil saturated before and after $\mathrm{CO}_{2}$ laser irradiation.

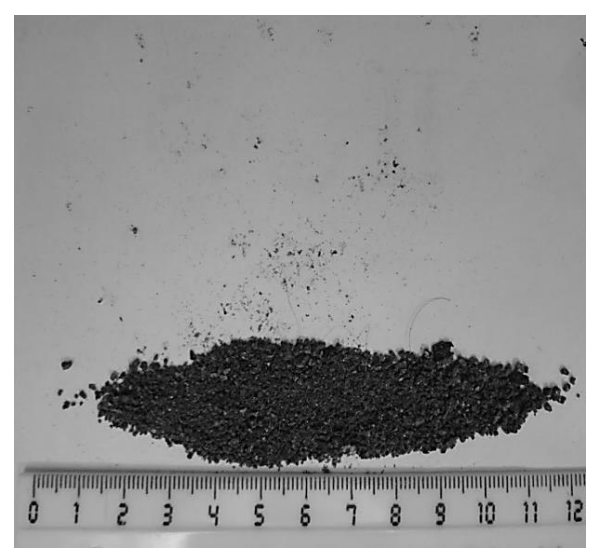

Figure 5. Limestone cutting during laser drilling laboratory process.

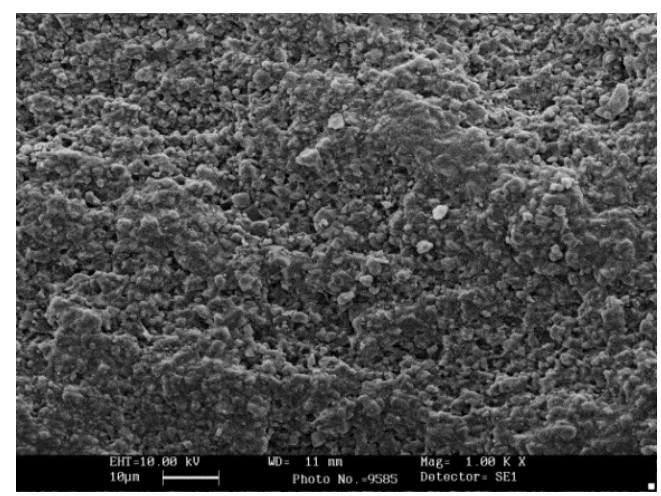

(a)

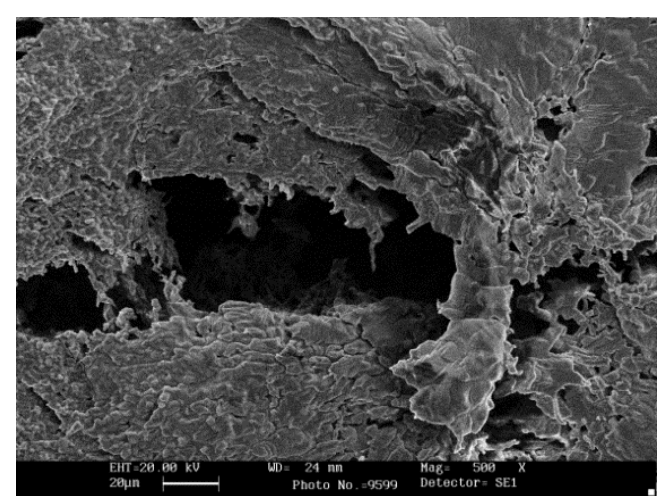

(b)

Figure 6. SEM images of limestone surface included heavy crude oil saturated (a) Before $\mathrm{CO}_{2}$ laser irradiation; (b) After 150 second $\mathrm{CO}_{2}$ laser irradiation. 
In all cases we observed the limestone surface included in-situ heavy oil was generating propagating many fractures. By increasing the time of irradiation of laser beam, large melted area on surface of limestone is created and the fractures develop whole the body and surface.

During laser-limestone interaction, the heavy oil in the pore size of samples of limestone surface absorbed the visual light of $\mathrm{CO}_{2}$ laser which can effected on absorbing the heat energy from the laser beam, it heated up and during the process the thermal fracturing and thin melting section is created.

Figures 7(a) and (b) displays the SEM images of limestone surface included dry and saturated samples by light oil before and after irradiating by a carbon dioxide laser beam. In this case we observed creation of thermal fractures are smaller than following images shown in Figure 6, but increasing the porosity were observed undeniable in the structure.

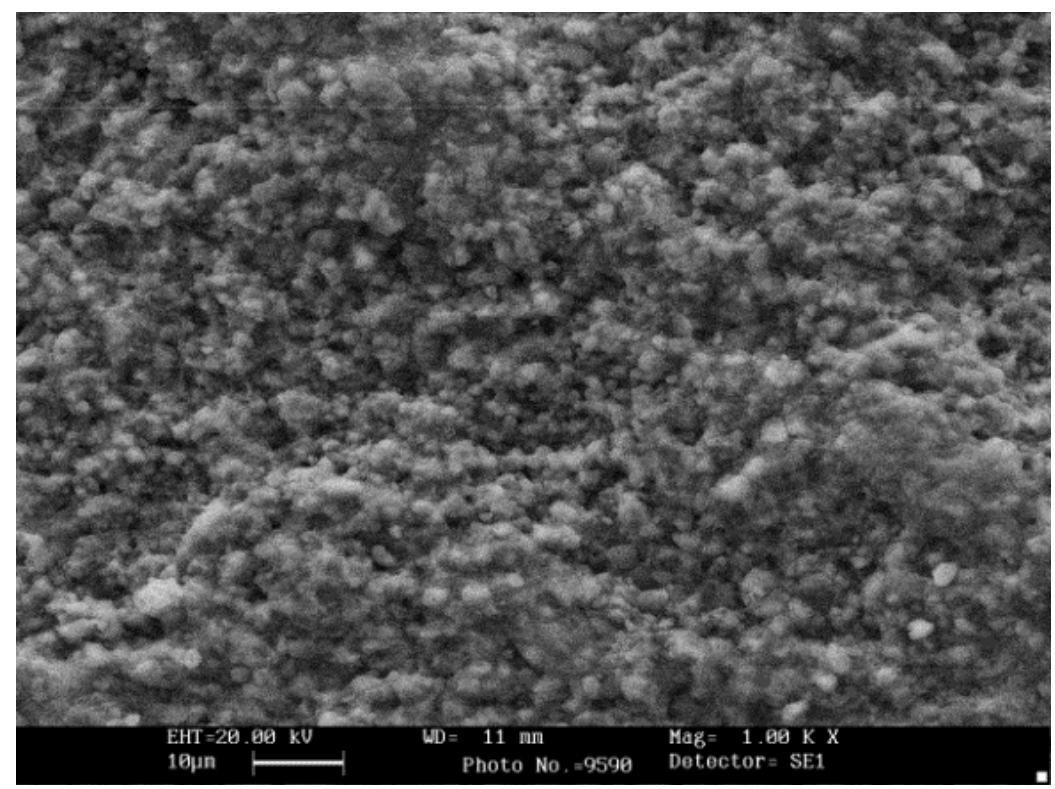

(a)

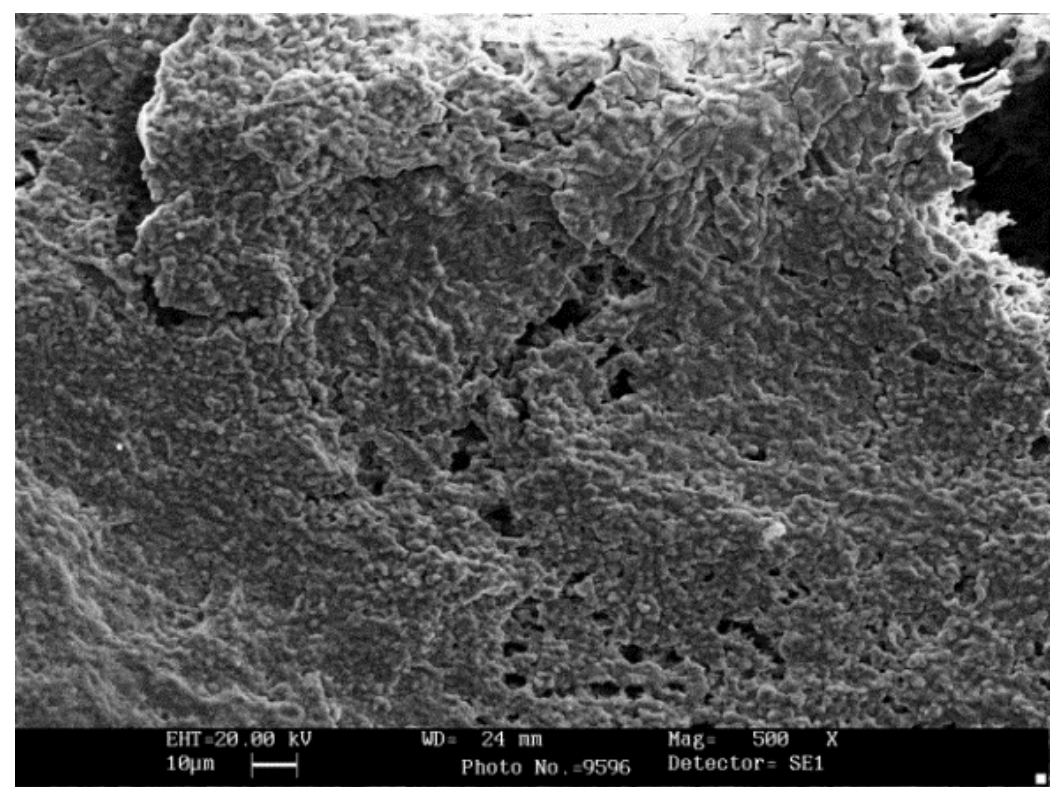

(b)

Figure 7. SEM images of limestone surface included light crude oil saturated (a) Before $\mathrm{CO}_{2}$ laser irradiation; (b) After 150 second $\mathrm{CO}_{2}$ laser irradiation. 
Comparing Figures 6 and 7 showed the type of oil which is saturated in limestone is an important parameter in absorption of light and energy beam and thermal fracturing during laser drilling process in the size of laboratory experiments.

It should be noted that during the erosion and ablation in the laser drilling operation in the experimental rocks of considered field, given the capability of the field, the formation and field lithology we observed the creation of fractures at the level of micro and nano simultaneously whose vacant spaces were positive. However, the reservoir and some others were neutral; these fractures can be created by the rate of crude oil absorption. Recently problem in drilling the oil and gas wells industry occurred by: drilling in hard formations like cap rocks and anhydride requires more traveling times for changing bits made by steel or diamond in rotary system; the key to solution of this fault since the laser might allow for non-contact or non-rotating drilling method. Reunite and anhydride are some of the most difficult rocks to be drilled by lasers. No report had been given on the actual effect.

\subsection{Drilling Optimization}

The new methods for drilling oil and gas wells are necessary and tool manufacturers have been made up significant progress to improving the upstream technologies in past decades. These technologies could lead directly to down hole drilling operation, but since 10 years ago petroleum, electronic and physics engineers have been focused on optimizing the drilling process. The industry requires a new methodology to help drilling operators and conductors by reaching the reservoir oil in less time periodic. Actually, once in the past a bit was on bottom and drilling tools were ahead, the manufacturer companies had little influence on a driller's decision to increase bit performance or to survive adversity. To help solve this issue, a new real time drilling parameter system was designed to optimize applied drilling parameters on a step by step basis.

To reach this goal it should be noted that laser industry helped over whelmed assist by focusing on rock texture parameters and interactions between laser and rock which could be thermal or photochemical interactions. Thermal interactions could lead the rock samples to expand and made plastic fractures which are damaged the rock surface and body. This could make the samples break during less amount of energy. This process is rock weakening which is obvious in the whole images in Figures 6 and 7. These parameters could show their influence on drilling operation. In this paper we shown that A central element in this work process is the real-time display and proved that using high power laser system during drilling operations might be helpful to improve the ROP and effect of laser drilling on the cost of every single foot of drilling process with lowering the cost to the consumer and improving the economy. As the matter of fact, a critical cost in future deep oil and gas formations recovery is the cost to drilling and the tools during this operation. These costs are dominated by the rate of penetration that becomes extremely important and needed to be focused on when we are in increasing depth process.

The final analysis in this work is data analysis that increases operating efficiency look like rate of penetration parameters to reduce drilling costs (Table 1). Then all parameters should be noticed and one of the great parameters that effect on drilling process is ROP. To show the rate of penetration during laser $\mathrm{CO}_{2}$ laboratory process in heavy oil saturated limestone and light oil saturated limestone we represent the ROP with time Table 1. In this table we showed that drilling operation in heavy oil saturated samples were effective than light oil saturated samples. This could relate to the absorption coefficient of crude oil in situ of porous medium.

This amount of operation with same rock samples with different in situ oil saturated could release the information about greater rock weakening during the heavy oil saturated reservoirs than the light oil saturated reservoirs.

\section{Conclusion}

In this paper we focused on laser drilling process in the size of laboratory experiments. And the results showed:

Table 1. The rate of penetration of laser beam on limestone rock at $150 \mathrm{Sec}$.

\begin{tabular}{cc} 
Materials & The Rate of Penetration (mm) \\
\hline Light oil saturated limestone & 20.4 \\
Heavy oil saturated limestone & 52.3 \\
\hline
\end{tabular}


- $\mathrm{CO}_{2}$ laser can reach the greater ROP to compare with conventional drilling operations.

- Gas lasers, such as $\mathrm{CO}_{2}$ can be more effective than the solid state lasers in this progress.

- Lasers can make several cracks on rock type and drill it after that process. Those cracks can weaken the samples.

- Inside fluid absorption can be effective during laser drilling.

- Dry samples are not effected in inside heating process caused by inside pore fluid of samples.

- Some sort of crude oils which are heavier than the others can absorb highly amount of laser energy in time.

- In samples with heavy oil saturated we can observe the greater fractured initiation and propagation.

\section{References}

[1] Graves, R.M., Batarseh, S., Parker, R.A. and Gahan, B.C. (2002) Temperature Induced by High Power Lasers: Effects on Reservoir Rock Strength and Mechanical Properties. SPE/ISRM Rock Mechanics Conference, Irving, 2002. http://dx.doi.org/10.2118/78154-MS

[2] Clarke, J.A. and Profeta III, J.A. (2004) Laser Micro-Drilling Applications. Proceeding of the 2004 Advanced Laser Applications Conference and Exposition, Michigan.

[3] Bazargan, M., Habibpour, M., Jalalyfar, H. and Granmayeh, A. (2012) Using the Laser Irradiation to Improve the Rate of Production of Iran South West Formation. SPE-163284-MS, SPE Kuwait International Petroleum Conference and Exhibition Held in Kuwait City, Kuwait, 10-12 December 2012.

[4] Bakhtbidar, M., Ghorbankhani, M., Kazemi Afseh, M.R. and Alimohammadi, M. (2011) Labratory Experiments Investigation of Effects of Lasers Energy on a Variety Rock Types: An Exploration Innovative Technology. 73rd EAGE Conference \& Exhibition.

[5] Xu, Z., Reed, C.B., Graves, R. and Parker, R. (2004) Rock Perforation by Pulsed Nd:YAG. Proceeding of the 23rd International Congress on Applications of Lasers and Electro-Optics, San Francisco.

[6] Bazargan, M., Madani, A., Sharifi, H., Jalalyfar, H., Ghassemalaskary, K. and Rostamian, A. (2013) Utilization of Lasers in Petroleum Drilling Industry. IPTC-17019-MS.

[7] Bazargan, M., Jalalyfar, H., Koohian, A. and Habibpour, M. (2013) Feasibility of Using Laser Bit Beside of Common Bits to Drilling Slim Holes. IPTC-16453-MS.

[8] Parker, R., Xu, Z., Reed, C., Graves, R. and Gahan, B. (2004) Drilling Large Diameter Holes in Rocks Using Multiple Laser Beams. Proceedings of the 23rd International Congress on Applications of Lasers and Electro-Optics, San Francisco.

[9] Xu, Z., Reed, C.B., Parker, R.A., Gahan, B.C., Graves, R.M., Batarsah, S. and Figueroa, H. (2002) Laser Rock Drilling by A Super-Pulsed $\mathrm{CO}_{2}$ Laser Beam. 21st International Conference on Applications of Lasers and Electro-Optics (ICALEO-2002), Scottsdale, Az.

[10] Parker, R.A., Gahan, B.C., Graves, R.M., Batarseh, S., Xu, Z.Y. and Reed, C.B. (2003) Laser Drilling: Effects of Beam Application Methods on Improving Rock Removal. Synopsis of Paper SPE 84353 Presented at the SPE Annual Technical Conference and Exhibition Held in Denver, Colorado, 5-8 October 2003.

[11] Graves, R.M., Araya, A., Gahan, B.C. and Parker, R.A. (2002) Comparison of Specific Energy between Drilling with High Power Lasers and Other Drilling Methods. Synopsis of Paper SPE 77627 Presented at the SPE Annual Technical Conference and Exhibition Held in San Antonio, Texas, 29 September-2 October 2002.

[12] Graves, R.M. and O’Brien, D.G. (1999) Star Wars Laser Technology for Gas Drilling and Completions in the 21st Century. Synopsis of Paper SPE 56625 Presented at the 1999 SPE Annual Technical Conference and Exhibition Held in Houston, Texas, 3-6 October 1999.

[13] Graves, R.M. and O’Brien, D.G. (1999) Star Wars Laser Technology Applied to Drilling and Completing Gas Wells. Synopsis of Paper SPE 49259 Presented at the 1998 SPE Annual Technical Conference and Exhibition Held in New Orleans, Louisiana, 27-30 September 1999.

[14] Gahan, B.C. and Parker, R.A. (2001) Laser Drilling: Determination of Energy Required to Remove Rock. Synopsis of Paper SPE 71466 Presented at the 2001 SPE Annual Technical Conference and Exhibition Held in New Orleans, Louisiana, 30 September-3 October 2001.

[15] Pooniwala, S. (2006) Lasers: The Next Bit. SPE Eastern Regional Meeting, Canton, Ohio.

[16] Batarseh, S., Gahan, B.C., Graves, R.M. and Parker, R.A (2003) Well Perforation Using High-Power Lasers. SPE 84418, October 2003.

[17] Gahan, B.C., Batarseh, S., Watson, R. and Deeg, W. (2005) Effect of Downhole Pressure Conditions on High-Power Laser Perforation. SPE 97093, October 2005. 
[18] Ahmadi, M., Erfan, M.R., Torkamany, M.J. and Safian, Gh.A. (2011) Optics \& Laser Technology, 43, $226-231$. http://dx.doi.org/10.1016/j.optlastec.2010.06.018

[19] Zekri, Y., Shedid, S.A. and Alkashef, H. (2001) Use of Laser Technology for the Treatment in Carbonate Formation. SPE Annual Technical Conference and Exhibition, New Orleans, 30 September-3 October 2001.

[20] Sinha, P. and Gour, A. (2006) Laser Drilling Research and Application: An Update. SPE/IADC Indian Drilling Technology Conference and Exhibition, Mumbai, India. http://dx.doi.org/10.2118/102017-MS

[21] Parker, R.A., Gahan, B.C. and Graves, R.M. (2003) Laser Drilling: Effect of Beam Application Methods on Improving Rock Removal. SPE Annual Technical Conference and Exhibition, Denver, 5-8 October 2003.

[22] Bechtold, P., Eiselen, S. and Schmidt, M. (2010) Physics Procedia, 5, 525-531.

[23] Ng, G.K.L. and Li, L. (2001) Optics \& Laser Technology, 33, 393-402. http://dx.doi.org/10.1016/S0030-3992(01)00048-2

[24] Ion, J.C. (2006) Laser Processing of Engineering Materials Principles, Procedure and Industrial Application. Englische Bücher..

[25] Poprawer, R., Schulz, W. and Schmitt, R. (2010) Physics Procedia, 5, 1-18.

[26] Carstens, J.P. and Brown, C.O. (1971) Rock Cutting by Laser. Fall Meeting of the Society of Petroleum Engineers of AIME, New Orleans, 3-6 October 1971.

[27] Sheng, P. and Chryssolouris, G. (1994) Journal of Material Processing Technology, 43, 125-144. http://dx.doi.org/10.1016/0924-0136(94)90017-5

[28] Salonitis, K., Stournaras, A., Tsoukantas, G., Stavropoulos, P. and Chryssolouris, G. (2007) Journal of Material Processing Technology, 183, 96-103. http://dx.doi.org/10.1016/j.jmatprotec.2006.09.031

[29] Low, D.K.Y. and Li, L. (2001) Optics \& Laser Technology, 33, 515-522. http://dx.doi.org/10.1016/S0030-3992(01)00074-3 